\title{
Copper-promoted hydration and annulation of 2-fluorophenylacetylene derivatives: from alkynes to benzo[b]furans and benzo[b]thiophenes
}

\author{
Yibiao Li ${ }^{* 1}$, Liang Cheng ${ }^{1}$, Xiaohang $\mathrm{Liu}^{2}$, Bin $\mathrm{Li}^{1}$ and Ning Sun ${ }^{1}$
}

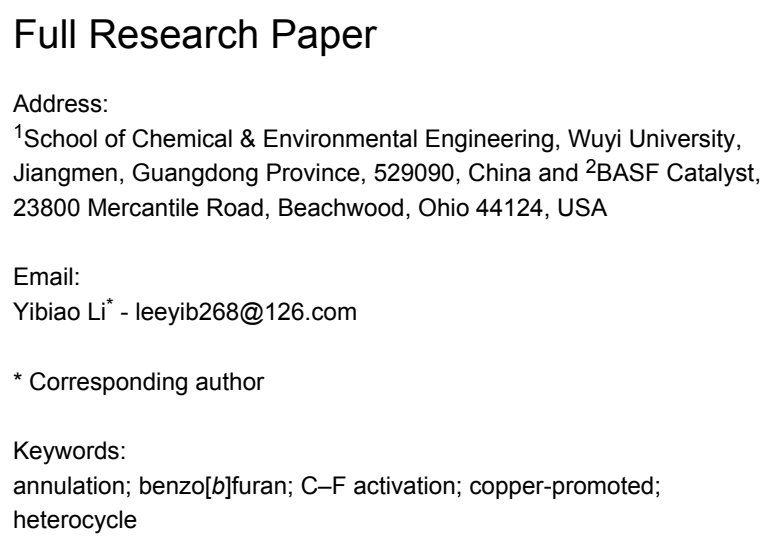

Beilstein J. Org. Chem. 2014, 10, 2886-2891. doi:10.3762/bjoc. 10.305

Received: 23 July 2014

Accepted: 20 November 2014

Published: 04 December 2014

Associate Editor: D. O'Hagan

(c) 2014 Li et al; licensee Beilstein-Institut. License and terms: see end of document.

\begin{abstract}
An efficient copper-promoted hydration reaction and its application in the synthesis of benzo[b]furan and benzo[b]thiophene derivatives is presented starting from readily available 2-fluorophenylacetylene derivatives. The key annulation step involves the hydration of the $\mathrm{C}-\mathrm{F}$ bond of 2-fluorophenylacetylene derivatives followed by an intramolecular annulation to afford benzo[b]furan and benzo $[b]$ thiophene derivatives. Moreover, structurally important 2,2'-bisbenzofuran scaffolds are provided in good yields.
\end{abstract}

\section{Introduction}

The development of general and efficient methodologies for the synthesis of complex heterocycle skeletons has received much attention in the past decades. Among the most ubiquitous heterocyclic moieties in natural and bioactive products are the benzo[b]furan and benzo[b]thiophene units [1-8]. Despite the existence of established methods for the synthesis of benzo[b]furan and benzo[ $b]$ thiophene derivatives, the development of more convenient methods is of significant importance [9-14]. Commonly, the preparation of 2-substituted benzo[b]furans involves the usage of 2-halophenols as reaction precursors (Scheme 1a) [15-18], which can be cumbersome due to the precursors' instability and the protecting and deprotecting steps necessary to synthesize the precursors [19-23]
Ackermann et al. utilized bromo- and iodo-substituted phenylacetylene in their $\mathrm{TiCl}_{4}$-catalyzed intramolecular nucleophilic annulation process (Scheme 1b) [24]. But this method involves a two-step process and the usage of two different metal salts may complicate further processing. The direct design of a Pd or $\mathrm{Cu}$-catalyzed one-pot synthesis of benzo[b]thiophenes from 2-bromoalkynylbenzenes and a thiol derivative has eliminated these problems to a large extent [25-29]. Nevertheless, the direct synthesis of benzo[b]furans from 2-haloalkynylbenzenes and the usage of 2-fluorophenylacetylene derivatives as substrates continues to represent a challenge. Indeed, Tsuji and co-workers have developed a transition metal-free process for the synthesis of benzo[b]furans from 2-fluorophenylacetylene 

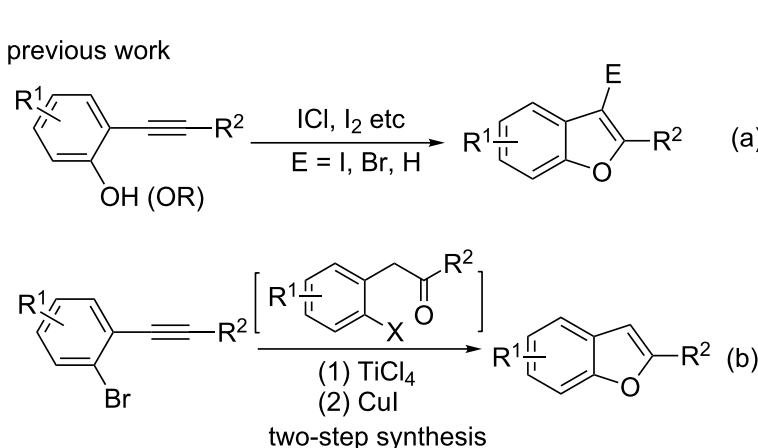

this work

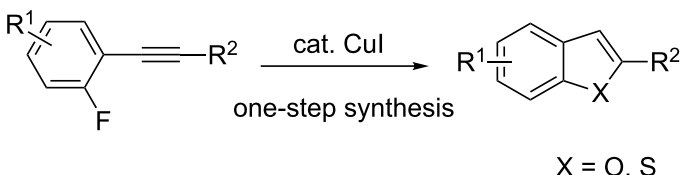

Scheme 1: Synthetic approaches to benzo[b]furans from 2-alkynylphenols, ketones and 2-fluorophenylacetylene derivatives.

derivatives. But the reaction requires conditions with a high reaction temperature for satisfactory yields. Unfortunately, only benzo[b]furans were obtained in this reaction [30].

Typically, the aryl halides used in the annulation reactions are iodides and bromides. It is rare to employ aryl fluorides because of their low reactivity [31-33]. To extend the application of our strategy of the copper-catalyzed synthesis of heterocycles, we report herein a one-pot process for the synthesis of benzo[b]furans and benzo[b]thiophenes with 2-fluorophenylacetylene derivatives as precursors (Scheme 1c).

\section{Results and Discussion}

We report an efficient synthesis of functionalized benzo[b]furans from commercially available alkynes by a copper-catalyzed, intramolecular annulation process. Initially, our investigation commenced with the annulation of (2-(2fluorophenyl)ethynyl)benzene (1a) to give the corresponding product 2-phenylbenzofuran (2a) by using 2 equiv $\mathrm{KOH}$ as a base under various conditions. In the presence of the $\mathrm{Pd}\left(\mathrm{PPh}_{3}\right)_{4}$ catalyst the reaction of (2-(2-fluorophenyl)ethynyl)benzene in $\mathrm{CH}_{3} \mathrm{CN}$ does not give any corresponding product (Table 1 , entry 1). The usage of $\mathrm{CuCl}$ and 1,10-phenanthroline (1,10phen) as a ligand in $\mathrm{CH}_{3} \mathrm{CN}$ at $80{ }^{\circ} \mathrm{C}$ showed that $2 \mathrm{a}$ could be isolated in $35 \%$ yield (Table 1, entry 2 ). The screening of the various solvents revealed that the solvent played an important role in this hydration and annulation process. Compared with the other solvents, DMSO is more suitable for the annulation process (Table 1, entries 2-4). These investigations revealed that the usage of $\mathrm{CuI}$ instead of $\mathrm{CuCl}$ as a catalyst resulted in the isolation of $\mathbf{2 a}$ in a satisfactory $88 \%$ yield after 4 hour
(Table 1, entry 5). To our delight, the use of 0.2 equiv of $\mathrm{KI}$ as an additive afforded 2a in a satisfactory $95 \%$ yield (Table 1, entry 6). The base loading had a strong influence on the yield with 2 equiv $\mathrm{KOH}$ being the optimal amount (Table 1, entries 7 and 12). Further screening of bases did not lead to better yields and confirmed that the reaction did not proceed in the presence of $\mathrm{CsCO}_{3}$ (Table 1, entry 8). Other catalytic systems, such as $\mathrm{Cu}(\mathrm{OAc})_{2}, \mathrm{Cu}(\mathrm{OTf})_{2}$ and $\mathrm{Cu}(\mathrm{acac})_{2}$, were less effective for this annulation process (Table 1, entries 9-11). A decrease in the temperature lowered the yield of the reaction (Table 1, entry 13). The importance of water was confirmed by a lower yield under dry conditions (Table 1, entry 14). In the absence of CuI, we found that the reaction of (2-(2-fluorophenyl)ethynyl)benzene with $\mathrm{KOH}$ in DMSO at $80{ }^{\circ} \mathrm{C}$ for $4 \mathrm{~h}$ gave $55 \%$ yield of the annulation product (Table 1, entry 15).

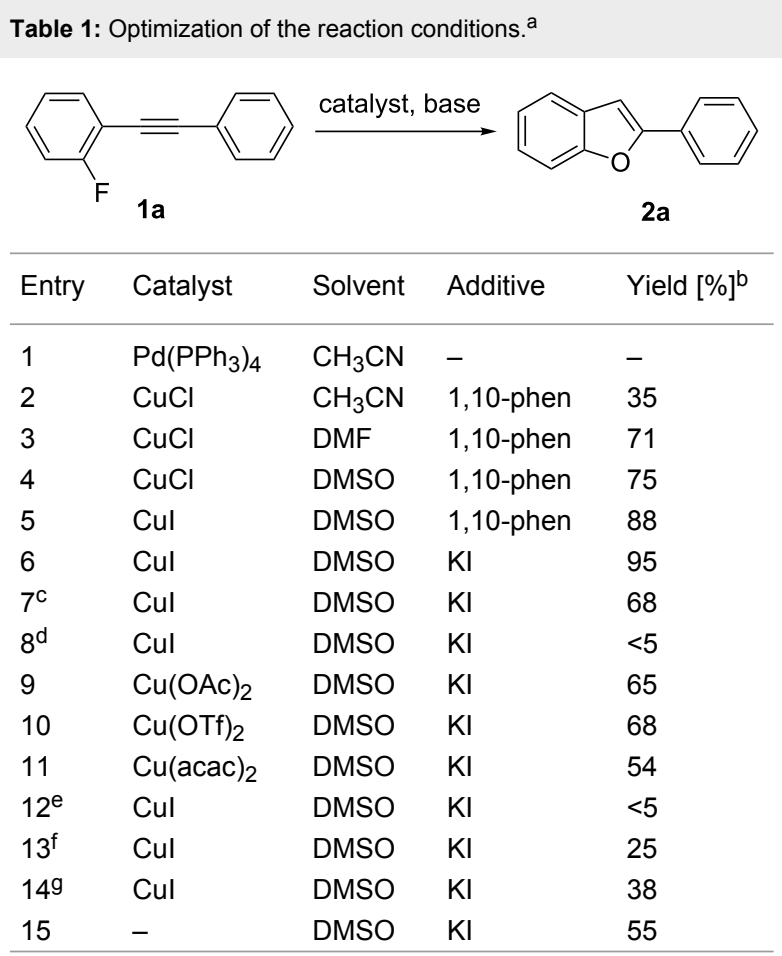

aReaction conditions: alkyne $1 \mathrm{a}(1.0 \mathrm{mmol})$, catalyst (10 $\mathrm{mol} \%)$, base (2.0 mmol), $\mathrm{H}_{2} \mathrm{O}(1.5 \mathrm{mmol})$ and additives $(0.2 \mathrm{mmol})$ in $3 \mathrm{~mL}$ of solvent at $80^{\circ} \mathrm{C}$ for $4 \mathrm{~h}$; byields are given for isolated products; $\mathrm{c}_{1}$ equiv $\mathrm{KOH}$ was used; ${ }^{\mathrm{d}} \mathrm{CsCO}_{3}$ instead of $\mathrm{KOH}$; ${ }^{\text {omitting } \mathrm{KOH} \text { and }}$ starting material recovered; ${ }^{f}$ reaction was carried out at $30^{\circ} \mathrm{C}$. gomitting $\mathrm{H}_{2} \mathrm{O}$ (dry conditions).

Next, we explored the scope and generality of the process by using the conditions for Tabe 1, entry 6. As shown in Scheme 2, substrates with either electron-donating or electron-withdrawing substituents on the benzene ring can undergo the reaction smoothly, and the corresponding benzo[b]furan products were obtained in good to excellent yields. The reaction tolerated a variety of substituents including $-\mathrm{Cl},-\mathrm{Br},-\mathrm{F}$, -OMe, 


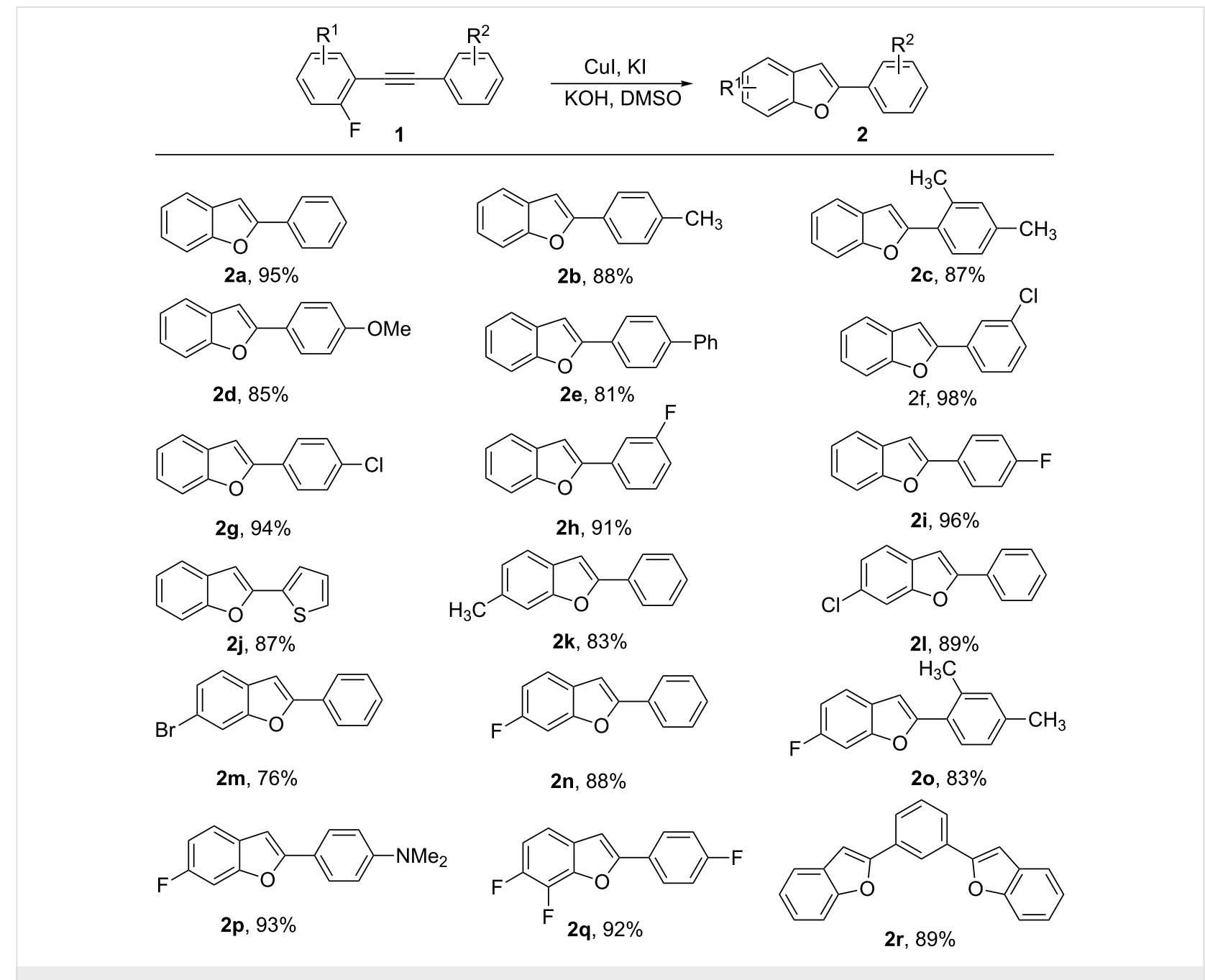

Scheme 2: Copper-promoted reaction of 2-fluorophenylacetylene derivatives to yield benzo[b]furans. Reaction conditions: Alkyne 1a (1.0 mmol), catalyst $(10 \mathrm{~mol} \%), \mathrm{KOH}(2.0 \mathrm{mmol}), \mathrm{H}_{2} \mathrm{O}(1.5 \mathrm{mmol})$ and $\mathrm{KI}(0.2 \mathrm{mmol})$ in $3 \mathrm{~mL}$ of DMSO at $80{ }^{\circ} \mathrm{C}$ for $4-8 \mathrm{~h}$; yields are given for isolated products.

$-\mathrm{NMe}_{2}$ and thiophenyl groups. The use of 2-fluorophenylacetylene derivatives with electron-withdrawing substituents as $\mathrm{R}^{2}$ afforded benzo[b]furan products in higher yields. It is noteworthy that the 2-(2-(2-fluorophenyl)ethynyl)thiophene was also successfully converted to 2-(thiophen-2-yl)benzofuran (2j) in good yields. Subsequently, the $\mathrm{R}^{1}$ substituent of the 2-fluorophenylacetylene derivatives was varied from hydrogen to other functional groups. Substituents at the ortho position of the benzyl group did not have an impact on the reaction yield. The presence of an additional electron-donating substituent marginally decreased the conversion of 2-fluorophenylacetylene derivatives resulting in products in moderate yields (Scheme 2, $\mathbf{2 k}$ and 2o). Interestingly, the $p$-fluoro atom was kept intact during the reaction and fluoro-substituted benzofuran was obtained (Scheme 2, 2q) [34-37]. This shows the good selectivity of the current reaction system. It should be emphasized that the 1,3-bis(2-(2-fluorophenyl)ethynyl)benzene was also successfully converted to benzo[b]furan $2 \mathbf{r}$ in good yield.
Unfortunately, when aliphatic alkynes were employed, the desired annulation products were formed in low yields.

The above studies dealt only with 1,2-diphenylethyne derivatives as a reactive group in the substrates. Inspired by the results of the nucleophilic annulation process, we wondered whether we could further explore the annulation of 1,3diynes, which have great synthetic potential in medicine and materials sciences [38-40]. For extensions, we used 1,4-bis(2fluorophenyl)buta-1,3-diyne as a substrate to investigate the possibility of this transformation. Similar to (2-(2-fluorophenyl)ethynyl)benzene, 1,4-bis(2-fluorophenyl)buta-1,3-diyne was able to offer the corresponding annulation products $2 \mathrm{~s}$ in $78 \%$ yield (Scheme 3 ).

To gain a deeper mechanistic understanding of the present catalytic process, the direct intramolecular annulation of 1-bromo-2-(2-(2-fluorophenyl)ethynyl)benzene and 1-chloro-2- 

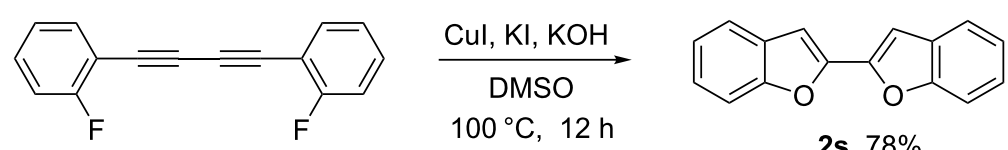

2s, $78 \%$

Scheme 3: Copper-promoted synthesis of 2,2'-bisbenzofuran derivatives.

(2-(2-fluorophenyl)ethynyl)benzene were performed, as shown in Scheme 4. In F/Br-substituted 1-bromo-2-(2-(2fluorophenyl)ethynyl)benzene, the fluoro moiety served as leaving group and gave 2-(2-bromophenyl)benzofuran (2t) as a major product. In F/Cl-substituted 1-chloro-2-(2-(2-fluorophenyl)ethynyl)benzene was able to offer the chloro-substituted product $2 \mathbf{v}$ as the only product. A reactivity order of $\mathrm{F}>\mathrm{Br}>\mathrm{Cl}$ can be derived from these data.

Reactions with $\mathrm{Na}_{2} \mathrm{~S} \cdot 9 \mathrm{H}_{2} \mathrm{O}$ as a nucleophile were successful, and the corresponding benzo $[b]$ thiophene products were obtained in high yields (Scheme 5). We obtained the best results with DMSO as the solvent and a reaction temperature of $60{ }^{\circ} \mathrm{C}$. Using the optimized reaction conditions, 3-chloro and 4-chloro substituted 2-fluoroalkynylbenzenes were reacted with $\mathrm{Na}_{2} \mathrm{~S} \cdot 9 \mathrm{H}_{2} \mathrm{O}$ to yield benzo[b]thiophenes in good yields.

The postulated reaction mechanism is depicted in Scheme 6 [25-29]. The catalytic cycle is initiated by the nucleophilic substitution of 2-fluorophenylacetylene derivative $\mathbf{1}$ with $\mathrm{OH}^{-}$. This might provide unstable 2-alkynylphenol A, which could then form the corresponding potassium phenolate intermediate B. The coordination of $\mathrm{CuI}$ with $\mathbf{B}$ may provide intermediate $\mathbf{C}$, and the subsequent addition to the $\mathrm{C}-\mathrm{C}$ triple bond gives the copper complex D. Protonolysis of intermediate $\mathbf{D}$ generates benzo $[b]$ furan 2 and regenerates the active catalyst species.

\section{Conclusion}

In summary, we have developed a new protocol for the synthesis of benzo[b]furan and benzo[b]thiophene derivatives

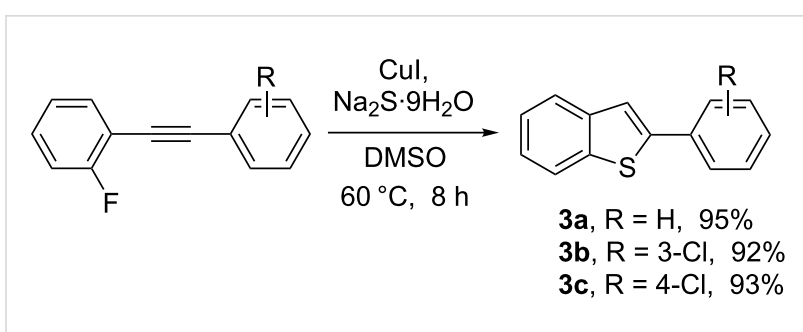

Scheme 5: Copper-promoted synthesis of benzo[b]thiophenes.<smiles>[R]C#Cc1ccccc1C(C)C(C)O</smiles>

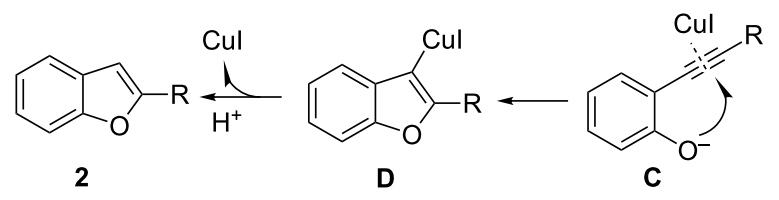

Scheme 6: Proposed mechanism for the annulation reaction.

starting from 2-fluorophenylacetylene derivatives. The hydration and annulation is catalyzed by $\mathrm{CuI}$ with $\mathrm{KOH}$ or $\mathrm{Na}_{2} \mathrm{~S} \cdot 9 \mathrm{H}_{2} \mathrm{O}$ as a base at $60-80{ }^{\circ} \mathrm{C}$ to give the corresponding products in moderate to good yields. Various functional groups are accepted resulting in a wide range of substituted benzo $[b]$ furans and benzo $[b]$ thiophenes. Further studies, which
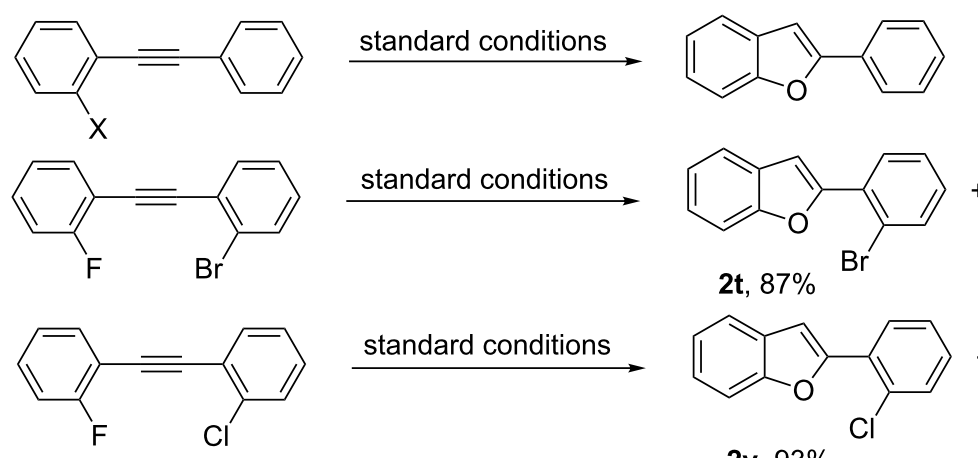

2a, $\mathrm{X}=\mathrm{Cl},<5 \%$

$\mathrm{X}=\mathrm{Br}, 32 \%$

$X=F, 95 \%$<smiles>BrC1=C(c2cc3ccccc3o2)C=C[C+]=C1</smiles>

2t, $87 \%$

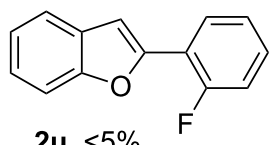

1

2v, $93 \%$<smiles></smiles>

2 w, not obtained 
are focused on the extension of the scope and the application of the reaction to the synthesis of bioactive products, are currently ongoing in our laboratory.

\section{Supporting Information}

\section{Supporting Information File 1}

Full experimental details and copies of NMR spectral data. [http://www.beilstein-journals.org/bjoc/content/ supplementary/1860-5397-10-305-S1.pdf]

\section{Acknowledgements}

We thank the National Natural Science Foundation of China (21302146), the Guangdong Natural Science Foundation (S2013040012354), the Foundation for Distinguished Young Talents in Higher Education of Guangdong (2013LYM_0094), and the Science Foundation for Young Teachers of Wuyi University (201210291040098) for financial support.

\section{References}

1. Wu, X.-F.; Neumann, H.; Beller, M. Chem. Rev. 2013, 113, 1-35. doi:10.1021/cr300100s

2. Zeni, G.; Larock, R. C. Chem. Rev. 2006, 106, 4644-4680. doi:10.1021/cr0683966

3. Lipshutz, B. H. Chem. Rev. 1986, 86, 795-819. doi:10.1021/cr00075a005

4. Lu, H.; Liu, G.-T. Planta Med. 1992, 58, 311-313. doi:10.1055/s-2006-961473

5. Navarro, E.; Alonso, S. J.; Trujillo, J.; Jorge, E.; Pérez, C. J. Nat. Prod. 2001, 64, 134-135. doi:10.1021/np9904861

6. Cacchi, S.; Fabrizi, G.; Goggiamani, A. Org. Biomol. Chem. 2011, 9, 641-652. doi:10.1039/c0ob00501k

7. Flynn, B. L.; Hamel, E.; Jung, M. K. J. Med. Chem. 2002, 45, 2670-2673. doi:10.1021/jm020077t

8. Palkowitz, A. D.; Glasebrook, A. L.; Thrasher, K. J.; Hauser, K. L.; Short, L. L.; Philips, D. L.; Muehl, B. S.; Sato, M.; Shetler, P. K.; Cullinan, G. J.; Pell, T. R.; Bryant, H. U. J. Med. Chem. 1997, 40, 1407-1416. doi:10.1021/jm970167b

9. Wang, X.; Liu, M.; Xu, L.; Wang, Q.; Chen, J.; Ding, J.; Wu, H. J. Org. Chem. 2013, 78, 5273-5281. doi:10.1021/jo400433m

10. Kraus, G. A.; Schroeder, J. D. Synlett 2005, 2504-2506. doi:10.1055/s-2005-872690

11. Katritzky, A. R.; Ji, Y.; Fang, Y.; Prakash, I. J. Org. Chem. 2001, 66, 5613-5615. doi:10.1021/jo010278p

12. Siddiqui, I. R.; Waseem, M. A.; Shamim, S.; Shireen; Srivastava, A.; Srivastava, A. Tetrahedron Lett. 2013, 54, 4154-4158. doi:10.1016/j.tetlet.2013.05.150

13. Eidamshaus, C.; Burch, J. D. Org. Lett. 2008, 10, 4211-4214. doi:10.1021/ol801510n

14. Liang, Z.; Hou, W.; Du, Y.; Zhang, Y.; Pan, Y.; Mao, D.; Zhao, K. Org. Lett. 2009, 11, 4978-4981. doi:10.1021/ol902157c

15. Zeni, G.; Larock, R. C. Chem. Rev. 2004, 104, 2285-2310. doi:10.1021/cr020085h

16. Cho, C.-H.; Neuenswander, B.; Lushington, G. H.; Larock, R. C. J. Comb. Chem. 2008, 10, 941-947. doi:10.1021/cc800120y
17. Cano, R.; Yus, M.; Ramón, D. J. Tetrahedron 2012, 68, 1393-1400. doi:10.1016/j.tet.2011.12.042

18. Liang, Y.; Tang, S.; Zhang, X.-D.; Mao, L.-Q.; Xie, Y.-X.; Li, J.-H. Org. Lett. 2006, 8, 3017-3020. doi:10.1021/ol060908f

19. Arcadi, A.; Cacchi, S.; Di Giuseppe, S.; Fabrizi, G.; Marinelli, F. Org. Lett. 2002, 4, 2409-2412. doi:10.1021/ol0261581

20. Okitsu, T.; Nakazawa, D.; Taniguchi, R.; Wada, A. Org. Lett. 2008, 10, 4967-4970. doi:10.1021/ol8020463

21. Yue, D.; Yao, T.; Larock, R. C. J. Org. Chem. 2005, 70, 10292-10296. doi:10.1021/jo051299c

22. Arcadi, A.; Cacchi, S.; Fabrizi, G.; Marinelli, F.; Moro, L. Synlett 1999, 1432-1434. doi:10.1055/s-1999-2839

23. Colobert, F.; Castanet, A.-S.; Abillard, O. Eur. J. Org. Chem. 2005, 3334-3341. doi:10.1002/ejoc.200500166

24. Ackermann, L.; Kaspar, L. T. J. Org. Chem. 2007, 72, 6149-6153. doi:10.1021/j0070887i

25. Sun, L.-L.; Deng, C.-L.; Tang, R.-Y.; Zhang, X.-G. J. Org. Chem. 2011, 76, 7546-7550. doi:10.1021/jo201081v

26. Ma, D.; Xie, S.; Xue, P.; Zhang, X.; Dong, J.; Jiang, Y. Angew. Chem., Int. Ed. 2009, 48, 4222-4225. doi:10.1002/anie.200900486

27. Kuhn, M.; Falk, F. C.; Paradies, J. Org. Lett. 2011, 13, 4100-4103. doi:10.1021/ol2016093

28. Guilarte, V.; Fernández-Rodríguez, M. A.; García-García, P.; Hernando, E.; Sanz, R. Org. Lett. 2011, 13, 5100-5103. doi:10.1021/ol201970m

29. Prasad, D. J. C.; Sekar, G. Org. Biomol. Chem. 2013, 11, 1659-1665. doi:10.1039/c3ob26915a

30. Tsuji, H.; Cantagrel, G.; Ueda, Y.; Chen, T.; Wan, L.-J.; Nakamura, E. Chem. - Asian J. 2013, 8, 2377-2382. doi:10.1002/asia.201300106

31. Amii, H.; Uneyama, K. Chem. Rev. 2009, 109, 2119-2183. doi: $10.1021 / \mathrm{cr} 800388 \mathrm{c}$

32. Grecian, S. A.; Hadida, S.; Warren, S. D. Tetrahedron Lett. 2005, 46, 4683-4685. doi:10.1016/j.tetlet.2005.04.111

33. He, C.-Y.; Fan, S.; Zhang, X. J. Am. Chem. Soc. 2010, 132, 12850-12852. doi:10.1021/ja106046p

34. Nie, J.; Guo, H.-C.; Cahard, D.; Ma, J.-A. Chem. Rev. 2011, 111, 455-529. doi:10.1021/cr100166a

35. O'Hagan, D. Chem. Soc. Rev. 2008, 37, 308-319. doi:10.1039/b711844a

36. Lectard, S.; Hamashima, Y.; Sodeoka, M. Adv. Synth. Catal. 2010, 352, 2708-2732. doi:10.1002/adsc.201000624

37. Cho, E. J.; Senecal, T. D.; Kinzel, T.; Zhang, Y.; Watson, D. A.; Buchwald, S. L. Science 2010, 328, 1679-1681. doi:10.1126/science.1190524

38. Matsuda, S.; Takahashi, M.; Monguchi, D.; Mori, A. Synlett 2009, 1941-1944. doi:10.1055/s-0029-1217537

39. Jacubert, M.; Provot, O.; Peyrat, J.-F.; Hamze, A.; Brion, J.-D.; Alami, M. Tetrahedron 2010, 66, 3775-3787. doi:10.1016/j.tet.2010.03.055

40. Pan, W.-B.; Chen, C.-C.; Wei, L.-L.; Wei, L.-M.; Wu, M.-J. Tetrahedron Lett. 2013, 54, 2655-2657. doi:10.1016/j.tetlet.2013.03.040 


\section{License and Terms}

This is an Open Access article under the terms of the Creative Commons Attribution License

(http://creativecommons.org/licenses/by/2.0), which permits unrestricted use, distribution, and reproduction in any medium, provided the original work is properly cited.

The license is subject to the Beilstein Journal of Organic Chemistry terms and conditions:

(http://www.beilstein-journals.org/bjoc)

The definitive version of this article is the electronic one which can be found at:

doi:10.3762/bjoc. 10.305 